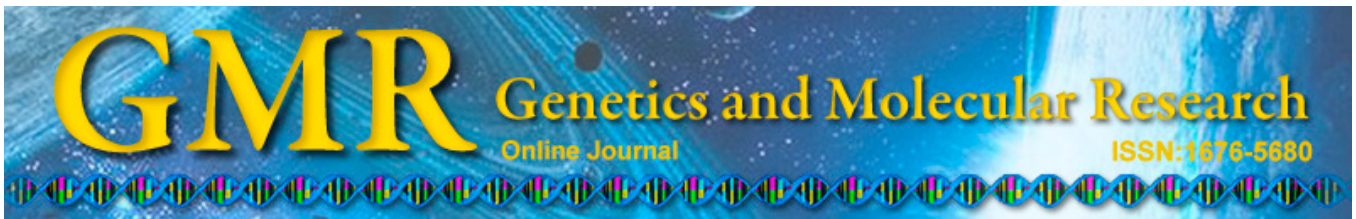

\title{
Genetic diversity and historical demography of the narrow-range endemic Alpine toad, Scutiger liupanensis, in the Liupan Mountains of central China
}

\author{
L.-N. Su ${ }^{1,2,3 *}$, H.-Z. Meng ${ }^{1,4 *}$ and X.-C. Li $^{1}$ \\ ${ }^{1}$ College of Life Sciences of Shaanxi Normal University, Xi'an, China \\ ${ }^{2}$ Shaanxi Institute of Zoology, Xi'an, China \\ ${ }^{3}$ Northwest Institute of Endangered Zoological Species, Xi'an, China \\ ${ }^{4}$ Middle School Affiliated to Shaanxi Normal University, Xi'an, China \\ *These authors contributed equally to this study. \\ Corresponding author: X.-C. Li \\ E-mail: xiaochen@snnu.edu.cn
}

Genet. Mol. Res. 14 (2): 4865-4878 (2015)

Received August 1, 2014

Accepted December 8, 2014

Published May 11, 2015

DOI http://dx.doi.org/10.4238/2015.May.11.19

\begin{abstract}
The genetic diversity and historical demography of the narrow-range endemic Alpine toad, Scutiger liupanensis, in the Liupanshan National Forest Park of central China were estimated using cytochrome $\mathrm{b}$ and cytochrome $\mathrm{c}$ oxidase subunit I (COI) from 85 individuals from five local populations. Both the haplotype diversity $\left(H_{\mathrm{d}}\right)$ and the nucleotide diversity $\left(P_{\mathrm{i}}\right)$ were very high. Phylogenetic analysis of the 63 haplotypes revealed two major clades, and an analysis of molecular variance attributed most of the variation to within populations. Mantel tests did not reveal an isolation by distance pattern of genetic divergence between populations, and SAMOVA showed no phylogeographic structure. The results of neutrality tests,
\end{abstract}


mismatch distribution analyses, and allelic frequency spectra suggest that a sudden demographic expansion occurred, and that high genetic variation is beneficial to the survival and development of this species.

Key words: Alpine toad; Genetic diversity; Historical demography; China

\section{INTRODUCTION}

Most studies that have investigated the effects of a narrow geographical range on genetic diversity have used plants (Hamrick et al., 1992; Gibson et al., 2008; Raduski et al., 2010), and have shown that geographical range plays an important role in shaping the genetic characteristics of plant populations (Hamrick and Godt, 1989; Gitzendanner and Soltis, 2000; Gibson et al., 2008). Some studies have found lower levels of genetic diversity in species with smaller ranges than their more widespread sibling species, due to genetic drift, bottlenecks, isolation, inbreeding, low levels of gene flow, and directional selection that promotes adaptation to the local environment (Hamrick and Godt, 1989; Hamrick et al., 1992; Torres-Diaz et al., 2007; Gibson et al., 2008). However, other studies have found that species with small ranges possess moderate to high levels of genetic variation (Gitzendanner and Soltis, 2000; Zhang et al., 2007; Crema et al., 2009), but very few narrowly endemic animals have been included in similar analyses.

Scutiger liupanensis (Pelobatidae) was first described by Huang (1985) in the Liupan Mountains of central China. The Liupan Mountains cover the southern part of the Ningxia Hui Autonomous Region and the eastern part of Gansu Province, central China; S. liupanensis inhabits a small mountain area. The species can be found near a few Alpine streams located in Jingyuan County, Ningxia, at an altitude of 1900 to $2500 \mathrm{~m}$ above sea level. These sites include Fragrant Water River (FWR), Cool Palace Gorge (CPG), Little South River (LSR), and Double-Dragon River (DDR) (Zhang et al., 1998). We also collected this species on Mount Xuanfengshan (MXF), Huating County, Gansu Province, thereby expanding the distribution of this species southward by $50 \mathrm{~km}$ (Figure 1). However, we failed to find this species elsewhere during extensive targeted searches over the entire Liupan Mountains.

S. liupanensis inhabits the northernmost part of the distribution of the genus Scutiger in China. Scutiger probably expanded north after the Quaternary glaciation and evolved into S. liupanensis, which has two neighboring conspecifics: Scutiger boulengeri and Scutiger ningshanensis. S. boulengeri is found in Yuzhong County and Jone County, Gansu Province, but Yuzhong is $150 \mathrm{~km}$ and Jone is $270 \mathrm{~km}$ away from the nearest location of S. liupanensis. The nearest location to the range of $S$. liupanensis is Ningshan County, Shaanxi Province, which is $250 \mathrm{~km}$ away from where $S$. ningshanensis is located (Figure 1).

Based on mitochondrial DNA data, the present study aimed to analyze the genetic diversity and historical demography of $S$. liupanensis, and to investigate the effects that a narrow geographical range and environment have on shaping the species' genetic characteristics and demographic dynamics. We predicted that there is only a low level of genetic diversity in this species, and that speciation probably resulted from an isolation or founder event. 


\section{MATERIAL AND METHODS}

\section{Sampling, DNA extraction, polymerase chain reaction (PCR) amplification, and sequencing}

A total of 85 S. liupanensis individuals were collected from five sites in the Liupan Mountains in 2011, including FWR, CPG, LSR, DDR, and MXF (Table 1, Figure 1). S. ningshanensis, collected from Pingheliang, Ningshan County, Shaanxi Province (33²8'27.984"N, $\left.108^{\circ} 31^{\prime} 31.008^{\prime \prime} \mathrm{E}\right)$, was selected as the outgroup.

The specimens were preserved in $100 \%$ ethanol and stored at $-20^{\circ} \mathrm{C}$. A continuous fragment (947 bp) of mitochondrial cytochrome b (cyt b) was amplified by conducting a PCR (MyCycler ${ }^{\mathrm{TM}}$, Bio-Rad), with forward (5'-CTT CCA TCC AAC ATC TCA GCA TGA TGA AA-3') and reverse (5'-ACA AGA CCA ATG CTT TAG TTA AGC TAC-3') primers (Li et al., 2009). A continuous fragment (644 bp) of mitochondrial cytochrome $\mathrm{c}$ oxidase subunit I (COI) was also amplified using PCR (MyCycler), with forward (LepF5'-ATT CAA CCA ATC ATA AAG ATA TTG G-3') and reverse (LepR5'-TAA ACT TCT GGA TGT CCA AAA AAT CA-3') primers (Hebert et al., 2004). The PCR products were purified using a purification kit (DC3511-02/3514-02 250 Preps, Biomiga Inc., San Diego, CA, USA). Sequencing reactions were carried out with PCR primers using the ABI Prism ${ }^{\circledR}$ BigDye $^{\mathrm{TM}}$ Terminator Cycle Sequencing Ready Reaction Kit, on an ABI 3730XL sequencer. All of the sequences have been deposited in GenBank databases under accession Nos. JX533722-JX533806 (S. liupanensis, cyt b), KC140474-KC140558 (S. liupanensis, COI), KC140561-KC140562 (S. ningshanensis, cyt b), and KC140559-KC140560 (S. ningshanensis, COI).

\section{Data analysis}

Sequences were aligned using ClustalX 1.83 (Chenna et al., 2003), and the aligned sequences were edited using BioEdit 7.0.9.0 (Hall, 1999). All the analyses were performed based on the combined mitochondrial DNA data. Haplotype inference was carried out using Collapse 1.2 (http://darwin.uvigo.es). The numbers of variable and parsimony informative sites were determined using DnaSP 5.10.01 (Librado and Rozas, 2009). The site-frequency spectrum (Donnelly et al., 2001) was implemented using DnaSP 5.10.01 (Librado and Rozas, 2009), in order to detect any excess singleton mutations.

Population and clade comparisons were made using the pairwise distance method, and the partitioning of genetic diversity to within and between populations was conducted using analysis of molecular variance (AMOVA) (Excoffier et al., 1992), using Arlequin 3.5.1.2 (Excoffier and Lischer, 2010) with 10,000 permutations. Mantel tests (Smouse et al., 1986) were also conducted in Arlequin 3.5.1.2 to assess the significance of the isolation by distance (IBD) between populations, with 10,000 random permutations in matrices of pairwise population $F_{\mathrm{ST}}$ values and geographical distances. Pairwise $F_{\mathrm{ST}}$ values between populations were estimated using Arlequin 3.5.1.2, and geographical distances between populations were calculated online at http://www.gpsvisualizer.com/calculators\#distance. Levels of gene flow were determined by the effective number of migrants (Nm; Hudson et al., 1992) between locations, using DnaSP 5.10.01 (Librado and Rozas, 2009).

Phylogenetic relationships between haplotypes were estimated using maximum parsimony (MP) analyses in PAUP* 4.0b10 (Swofford, 2002), and Bayesian analyses in MrBayes 


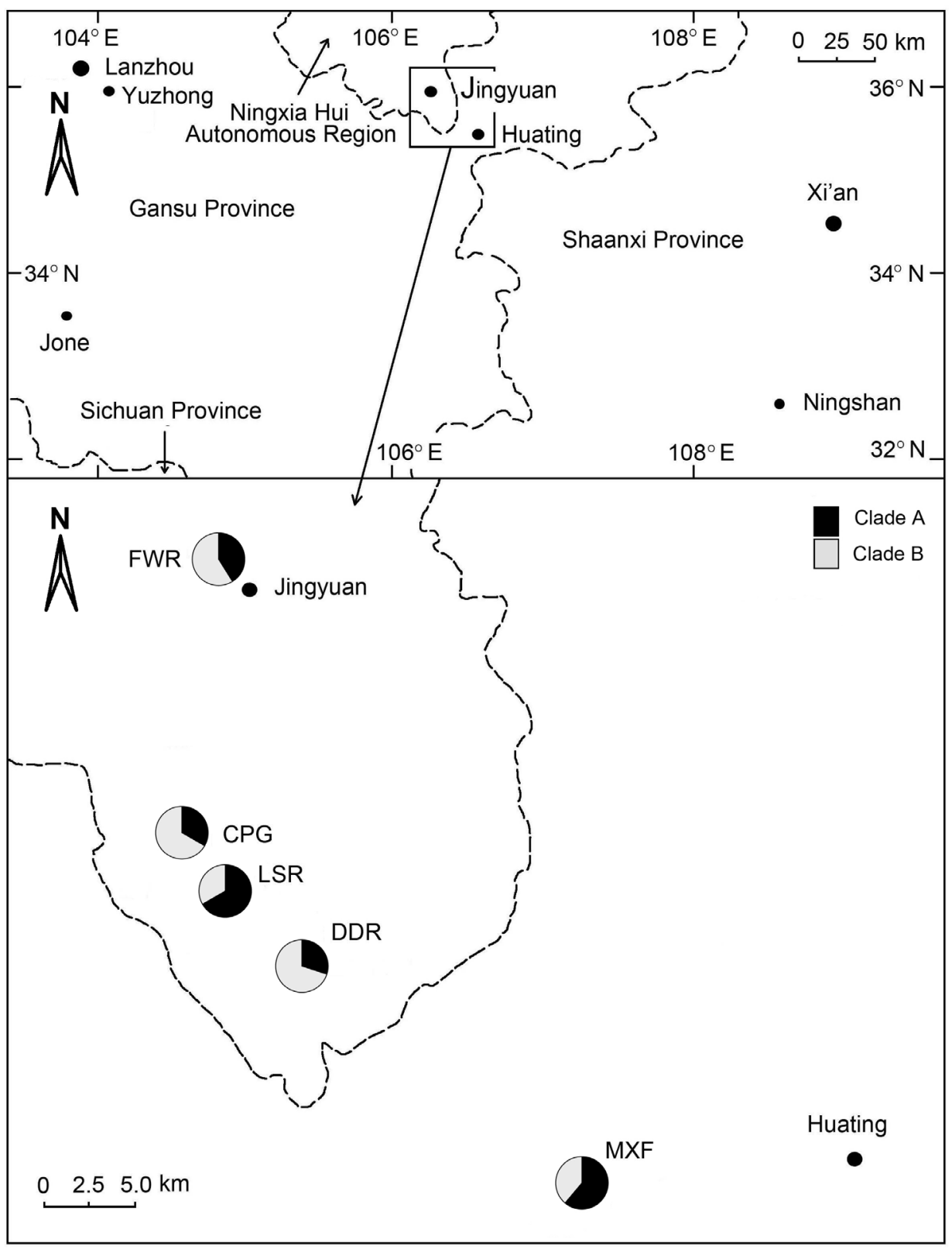

Figure 1. Sampling locations and clades in local populations.

3.1.2 (Ronquist and Huelsenbeck, 2003). The MP tree was inferred with a heuristic search strategy with random sequence addition, using the tree bisection-reconnection branch-swapping algorithm. The number of bootstrap replications was set to 1000. Bayesian analyses were performed over 1,000,000 generations, and trees were sampled every 100 generations. S. ningshanensis was used as the outgroup. A minimum spanning tree was built using TCS 1.21 (Clement et al., 2000). 
The spatial genetic structures of the haplotypes were analyzed using the program SAMOVA 1.0 (Dupanloup et al., 2002; http://web.unife.it/progetti/genetica/Isabelle/samova. $\mathrm{html}$ ), with 1000 permutations. The number of initial conditions was set at 100, as recommended by Dupanloup et al. (2002). The number $K$ of groups of populations was set at between 2 to 4 . The $K$ with the highest difference between groups of populations $\left(F_{\mathrm{CT}}\right)$ represented the best number of groups and the best population configuration.

Neutrality tests were conducted with Arlequin 3.5.1.2 (Excoffier and Lischer, 2010), and Fu's $\mathrm{F}_{\mathrm{S}}$ test $(\mathrm{Fu}, 1997)$ and Tajima's $D$ (Tajima, 1989) were used to detect evidence of recent demographic expansion within each inferred clade, under which negative values are expected (Schneider and Excoffier, 1999). In addition, an inference of population expansion events was performed using mismatch analysis (Rogers and Harpending, 1992; Rogers, 1995) in Arlequin 3.5.1.2, with the number of bootstrap replications set at 10,000, in order to explore the demographic history of the populations studied. Recent growth was expected to generate a unimodal distribution of pairwise differences between sequences (Rogers and Harpending, 1992). The validity of the expansion model was tested using the sum of squared deviations $(S S D)$ and Harpending's raggedness index $(R)$ of the observed and the expected mismatches. Arlequin was used to determine the haplotype $\left(H_{\mathrm{d}}\right)$ and nucleotide $\left(P_{\mathrm{i}}\right)$ diversities.

\section{RESULTS}

\section{DNA variation}

The total number of sites was 1591 (cyt b, 947; COI, 644), and there were no sites with alignment gaps or missing data. A total of 1448 positions were invariable (monomorphic) sites and 143 were variable (polymorphic) sites; the total number of mutations was 149. Sixtyfive positions were singleton variable sites (non-informative sites) and 78 were parsimony informative sites.

A total of 63 haplotypes were found, and the $H_{\mathrm{d}}$ and $P_{\mathrm{i}}$ of the total and individually sampled populations were high (Table 1). Fifty-three haplotypes were private, accounting for $84.1 \%$ of the total, whereas only ten haplotypes were common, and accounted for $15.9 \%$ of the total.

\begin{tabular}{|c|c|c|c|c|c|}
\hline Sampling sites & GPS coordinates & SS & Haplotypes (Frequency) & $P_{\mathrm{i}}$ & $H_{\mathrm{d}}$ \\
\hline FWR & $\begin{array}{l}35^{\circ} 29^{\prime} 59.14 " \mathrm{~N} \\
106^{\circ} 15^{\prime} 21.56^{\prime \prime} \mathrm{E}\end{array}$ & 17 & $\begin{array}{l}\text { Hap 4, Нар 8, Нар 14, Нар 22, Нар 24, Нар 28, Нар 30, } \\
\text { Hap } 33 \text { (4), Нар 38, Нар 46, Нар 51, Нар 52, Нар 53, Нар } 61\end{array}$ & $0.0137 \pm 0.0071$ & $0.9559 \pm 0.0436$ \\
\hline CPG & $\begin{array}{l}35^{\circ} 22^{\prime} 30.32^{\prime \prime} \mathrm{N} \\
106^{\circ} 17^{\prime} 46.20^{\prime \prime} \mathrm{E}\end{array}$ & 15 & $\begin{array}{l}\text { Hap 1, Hap 3, Нар 5, Нар 13, Нар 28, Нар } 33 \text { (3), Нар 40, } \\
\text { Hap } 44 \text { (2), Нар 49, Нар 56, Нар 58, Нар } 60\end{array}$ & $0.0137 \pm 0.0072$ & $0.9619 \pm 0.0399$ \\
\hline LSR & $\begin{array}{l}35^{\circ} 21^{\prime} 11.44^{\prime \prime} \mathrm{N} \\
106^{\circ} 18^{\prime} 49.91^{\prime \prime} \mathrm{E}\end{array}$ & 15 & $\begin{array}{l}\text { Hap 1, Hap 6, Нар 9, Hap 10, Hap 15, Нар 17, Нар 25, } \\
\text { Hap 29, Нар 31, Нар 32, Нар } 33 \text { (2), Нар 34, Нар 41, Hap } 54\end{array}$ & $0.0139 \pm 0.0073$ & $0.9905 \pm 0.0281$ \\
\hline DDR & $\begin{array}{l}35^{\circ} 20^{\prime} 23.28^{\prime \prime} \mathrm{N} \\
106^{\circ} 20^{\prime} 32.36^{\prime \prime} \mathrm{E}\end{array}$ & 20 & $\begin{array}{l}\text { Hap 12, Hap 16, Hap } 20 \text { (2), Hap 26, Hap 27, Hap } 33 \text { (3), } \\
\text { Hap 35, Hap 36, Hap 39, Hap 42, Hap 45, Hap 47, Hap 48, } \\
\text { Hap 51, Hap 55, Hap 57, Hap 63 }\end{array}$ & $0.0133 \pm 0.0068$ & $0.9789 \pm 0.0245$ \\
\hline MXF & $\begin{array}{l}35^{\circ} 10^{\prime} 11.97^{\prime \prime} \mathrm{N} \\
106^{\circ} 29^{\prime} 19.64^{\prime \prime} \mathrm{E}\end{array}$ & 18 & $\begin{array}{l}\text { Hap 2, Нар 6, Нар 7, Hap } 11 \text { (3), Hap 18, Hap 19, Hap 21, } \\
\text { Hар } 23 \text { (2), Нар 37, Нар } 37 \text { (2), Нар 43, Нар 50, Нар 59, Hap } 62\end{array}$ & $0.0153 \pm 0.0079$ & $0.9673 \pm 0.0298$ \\
\hline Total population & & 85 & & $0.0144 \pm 0.0071$ & $0.9751 \pm 0.0112$ \\
\hline
\end{tabular}

$\mathrm{SS}=$ sample size $H_{\mathrm{d}}=$ haplotype diversity; $P_{\mathrm{i}}=$ nucleotide diversity. 


\section{Phylogeographic structure}

The MP phylogenetic analysis of the 63 haplotypes revealed the existence of two clades (Figure 2). Clade A, which contained $50.8 \%$ of the total (32 haplotypes); and Clade B, which contained $49.2 \%$ of the total (31 haplotypes), were present in all five local populations (Figure 1, Table 1). No significant phylogeographic structure was found, since no corresponding relationships between clades and local populations were found, i.e., Clades A and B existed in all of the localities studied. Individuals from one population were distributed across different clades, and one clade contained individuals from different populations; therefore, there was no correlation between the clades and their geographical distributions. The Bayesian inference analysis yielded similar results: that the haplotypes were roughly divided into two groups. Clade A included haplotypes from Hap 1 to Hap 32, and Clade B included haplotypes from Hap 33 to Hap 63 in the Bayesian tree (Figures 2 and 3). The other haplotypes or branches did not cluster into a clade; however, the branch lengths were short.

Regarding the results of SAMOVA, the $F_{\mathrm{CT}}$ values were fairly low, and all of the $\mathrm{P}$ values (random value $\geq$ observed value) were higher than 0.05 . Therefore, SAMOVA tests failed to reveal any meaningful phylogeographic structure.

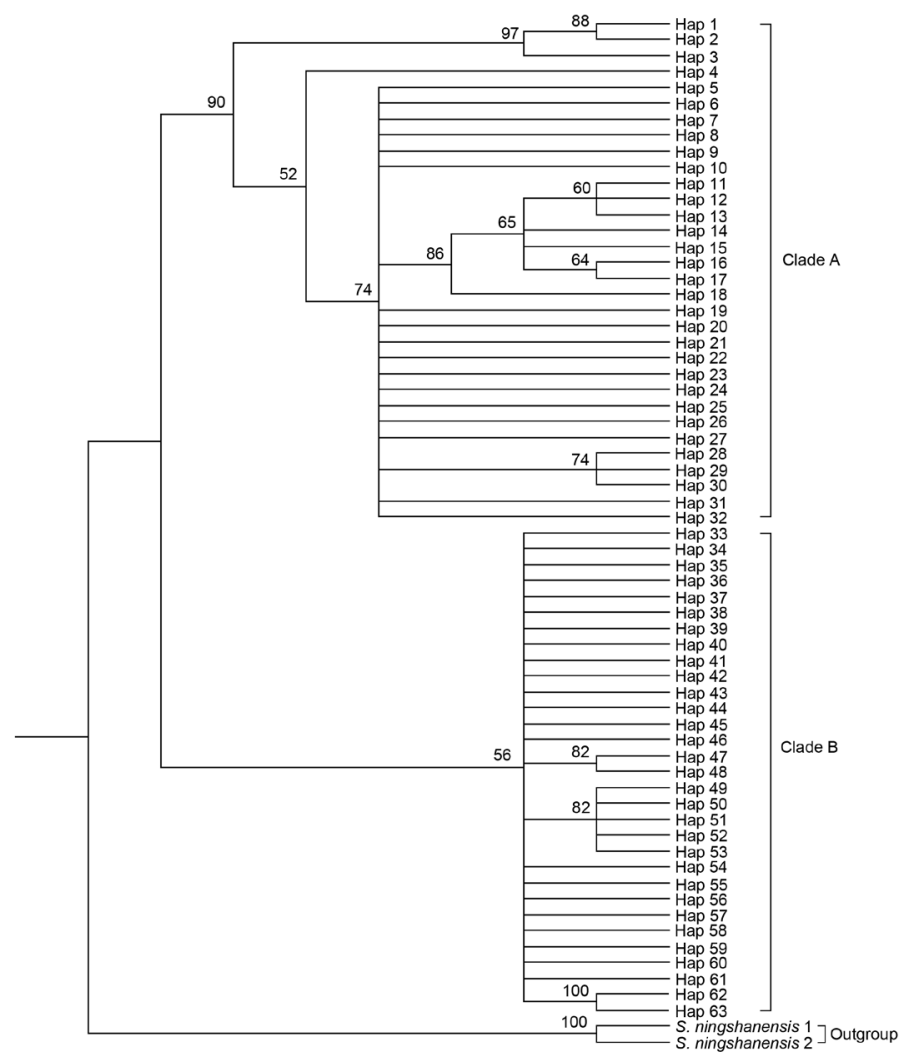

Figure 2. Maximum parsimony tree of haplotypes, rooted with two haplotypes from Scutiger ningshanensis. Numbers above branches represent the bootstrap values. 


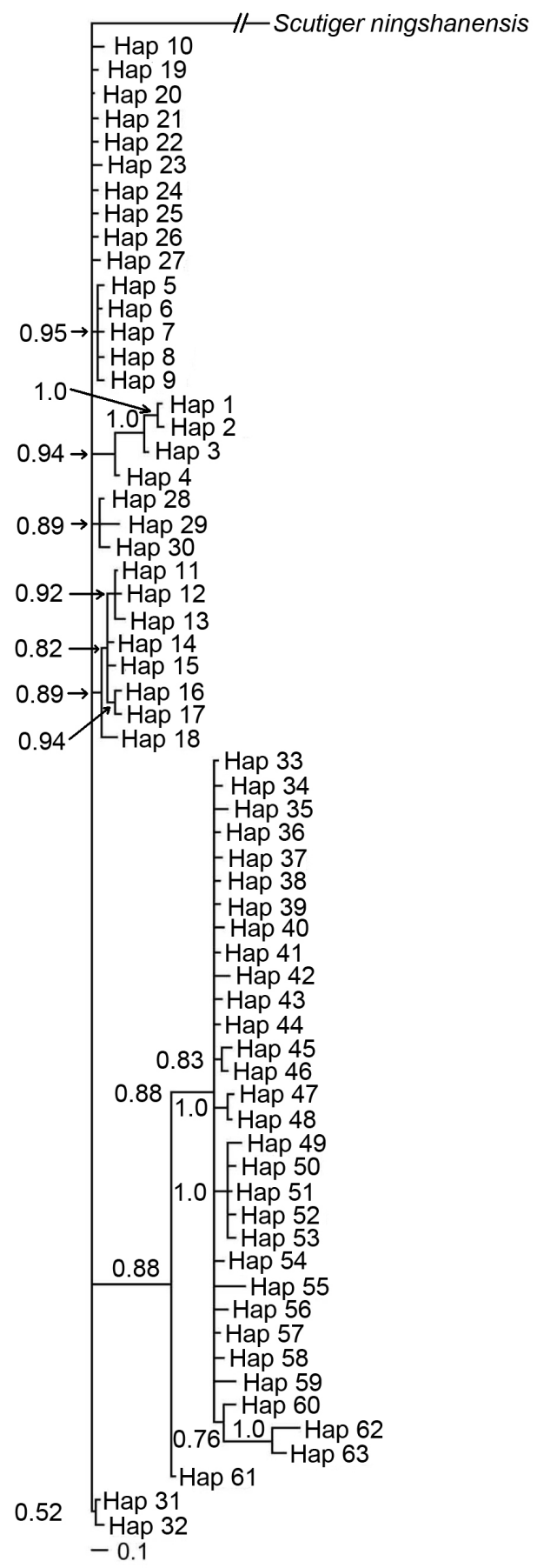

Figure 3. Bayesian inference tree of haplotypes, rooted with haplotype from Scutiger ningshanensis. Numbers represent the posterior probabilities, the bar represents branch length. 


\section{Population structure}

The results of AMOVA reveal that most of the variation was within populations (96.1\%), and differentiation between populations only contributed 3.9\% to the total (Table 2). The low genetic variation between populations confirmed the lack of a phylogeographic structure in this species. Gene flow, calculated using the $N_{\mathrm{m}}$, was high between most pairs of populations (Table 3 ), suggesting that there is a high level of gene flow between population of this species.

Table 2. Results of the analysis of molecular variance (AMOVA).
\begin{tabular}{lcccccc}
\hline Source of variation & d.f. & Sum of squares & Variance components & Percentage of variation & Fixation index \\
\hline Between populations & 4 & 75.101 & $0.45133^{\mathrm{Va}}$ & 3.9 & $\begin{array}{c}F_{\text {ST }}=0.03898 \\
\text { P (random value } \geq \text { observed value) }= \\
0.10574 \pm 0.00318\end{array}$ \\
Within populations & 80 & 890.123 & $11.12653^{\mathrm{Vb}}$ & & 96.1 & \\
Total & 84 & 965.224 & 11.57786 & & \\
\hline
\end{tabular}

d.f. $=$ degree of freedom. $F_{\mathrm{ST}}$, correlation within populations relative to total. Va represents the covariance component due to differences among the $\mathrm{G}$ populations (number of groups in the structure), while $\mathrm{Vb}$ represents the covariance component due to differences among haplotypes in different populations within a group (http:// cmpg.unibe.ch/software/arlequin35/man/Arlequin35.pdf).

Table 3. Gene flow (migrants per generation, $N_{\mathrm{m}}$ ) and $F_{\text {ST }}$ values.
\begin{tabular}{lccccc}
\hline Sampling sites & FWR & CPG & SSR & DDR & MXF \\
\hline FWR & - & -0.023 & 0.029 & -0.015 & 0.01 \\
CPG & -22.526 & - & 0.119 & -0.034 & 0.088 \\
LSR & 16.547 & -3.708 & - & 0.131 & -0.048 \\
DDR & -33.833 & -15.328 & 3.319 & - & -094 \\
MXF & 50.005 & 5.181 & -10.930 & 4.846 & - \\
\hline
\end{tabular}

$N_{\mathrm{m}}$ values are shown below the diagonal, and $F_{\mathrm{ST}}$ values are shown above the diagonal.

\section{Genetic differentiation}

Population comparisons showed no significant genetic differentiation between most local populations (Table 4), except for the population comparison of LSR and DDR. Clade comparisons showed significant genetic differentiation between Clades A and $\mathrm{B}\left(F_{\mathrm{ST}}=0.8343, \mathrm{P}=0.0\right)$.

\begin{tabular}{|c|c|c|c|c|c|}
\hline Local population & FWR (P value) & CPG ( P value) & LSR (P value) & DDR (P value) & MXF (P value) \\
\hline FWR & 0 & & & & \\
\hline \multirow[t]{2}{*}{ CPG } & -0.0227 & & & & \\
\hline & $(0.4873 \pm 0.0051)$ & 0 & & & \\
\hline \multirow[t]{2}{*}{ LSR } & 0.0294 & 0.1188 & & & \\
\hline & $(0.2296 \pm 0.0041)$ & $(0.0544 \pm 0.002)$ & 0 & & \\
\hline \multirow[t]{2}{*}{ DDR } & -0.0149 & -0.0335 & $0.1315^{*}$ & & \\
\hline & $(0.3896 \pm 0.0046)$ & $(0.6679 \pm 0.0043)$ & $(0.0429 \pm 0.002)$ & 0 & \\
\hline MXF & $\begin{array}{c}0.0097 \\
(0.2738 \pm 0.0045)\end{array}$ & $\begin{array}{c}0.0871 \\
(0.0842 \pm 0.0029)\end{array}$ & $\begin{array}{c}-0.0483 \\
(0.956 \pm 0.0019)\end{array}$ & $\begin{array}{c}0.0942 \\
(0.0682 \pm 0.0027)\end{array}$ & 0 \\
\hline
\end{tabular}

$* \mathrm{P}<0.05$. 
The Mantel test results did not reveal any significant correlation between the pairwisecalculated genetic distance and the pairwise-calculated geographical distance of the populations (regression coefficient $=-0.0015$, correlation coefficient $=-0.2816, \mathrm{P}=0.7838$ ), indicating the absence of an IBD pattern of genetic divergence for cyt $b$ and the COI sequence. This result suggests that the distribution of genetic variation was due to natural selection rather than to geographical separation. Therefore, the Mantel test results do not provide evidence of a large-scale geographical population structure in this species.

\section{Demographic history}

The results of the mismatch distribution analysis indicate that the $\mathrm{P}$ values for the $S S D \mathrm{~s}$ of the total population and Clade $\mathrm{B}$ were higher than 0.05 , and that the $\mathrm{P}$ values for the $R_{\mathrm{s}}$ of the total population and both clades were also higher than 0.05. The $\mathrm{P}$ values for Fu's $\mathrm{F}_{\mathrm{S}}$ test of the total population and both clades were lower than 0.01 , and for Tajima's $D$ of both clades they were lower than 0.05 or 0.01 (Table 5). All of the above P values suggest that the total population and both clades experienced a sudden population expansion. Tajima's $D$ value and Fu's $\mathrm{F}_{\mathrm{s}}$ test are sensitive to bottleneck effects and population expansion, resulting in more negative val-

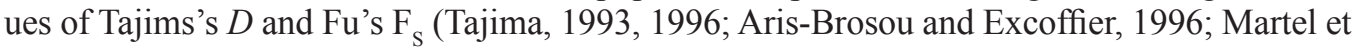
al., 2004), and the latter is the most sensitive to recent population growth (Fu, 1997). However, the mismatch distribution of the total population exhibited a frequency distribution of pairwise differences with multiple peaks (Figure 4). The allelic frequency spectrum of the entire population revealed that there was an excess of singleton mutations that did not fit the neutral model (Figure 5); the excess of singleton mutations was caused by a population expansion (RamosOnsins and Rozas, 2002). Both clades exhibited a star-shaped phylogeny network encircling the basic haplotypes, and the basic haplotypes had a wide distribution or a high frequency (Figure 6), indicating that an exponential expansion had occurred (Avise, 2000).

Table 5. Mismatch distribution analyses and neutrality tests.
\begin{tabular}{lllll}
\hline Clade & \multicolumn{1}{l}{$R$ SSD $(\mathrm{P}$ value $)$} & \multicolumn{1}{c}{$(\mathrm{P}$ value $)$} & \multicolumn{1}{c}{ Tajima's $D$ (P value $)$} & \multicolumn{1}{c}{ Fu's $\mathrm{F}_{\mathrm{S}}(\mathrm{P}$ value $)$} \\
\hline Clade $\mathrm{A}$ & $0.0972 * *(\mathrm{P}=0.0013)$ & $0.0133(\mathrm{P}=0.9914)$ & $-1.6348^{*}(\mathrm{P}=0.0293)$ & $-21.64194 * *(\mathrm{P}=0.0)$ \\
Clade $\mathrm{B}$ & $0.0 .0049(\mathrm{P}=0.7332)$ & $0.0124(\mathrm{P}=0.905)$ & $-2.4906 * *(\mathrm{P}=0.0003)$ & $-20.5201 * *(\mathrm{P}=0.0)$ \\
Total population & $0.0262(\mathrm{P}=0.4591)$ & $0.0047(\mathrm{P}=0.804)$ & $-0.6568(\mathrm{P}=0.2861)$ & $-22.3379 * *(\mathrm{P}=0.0007)$ \\
\hline
\end{tabular}

$* \mathrm{P}<0.05 ; * * \mathrm{P}<0.01 ; S S D=$ sum of squared deviation; $R=$ Harpending's raggedness index.

\section{DISCUSSION}

The Liupan Alpine toad is similar to the Tibetan Alpine toad S. boulengeri in morphology (Huang, 1985). The shortest distance between the ranges of these two species is $150 \mathrm{~km}$. We assumed that the former had evolved from the latter by an isolation or founder event. This assumption can now be rejected, since the Liupan Alpine toad possesses a high level of genetic diversity, which is usually low in species that originated from isolation or founder events.

High genetic diversity in narrowly endemic species could be associated with factors such as a long species history, which could accumulate many mutations, result in significant gene flow, and having experienced a recent population contraction, include multiple founder events, the maintenance of genetic diversity in refugia, hybridization, and the ability to sur- 

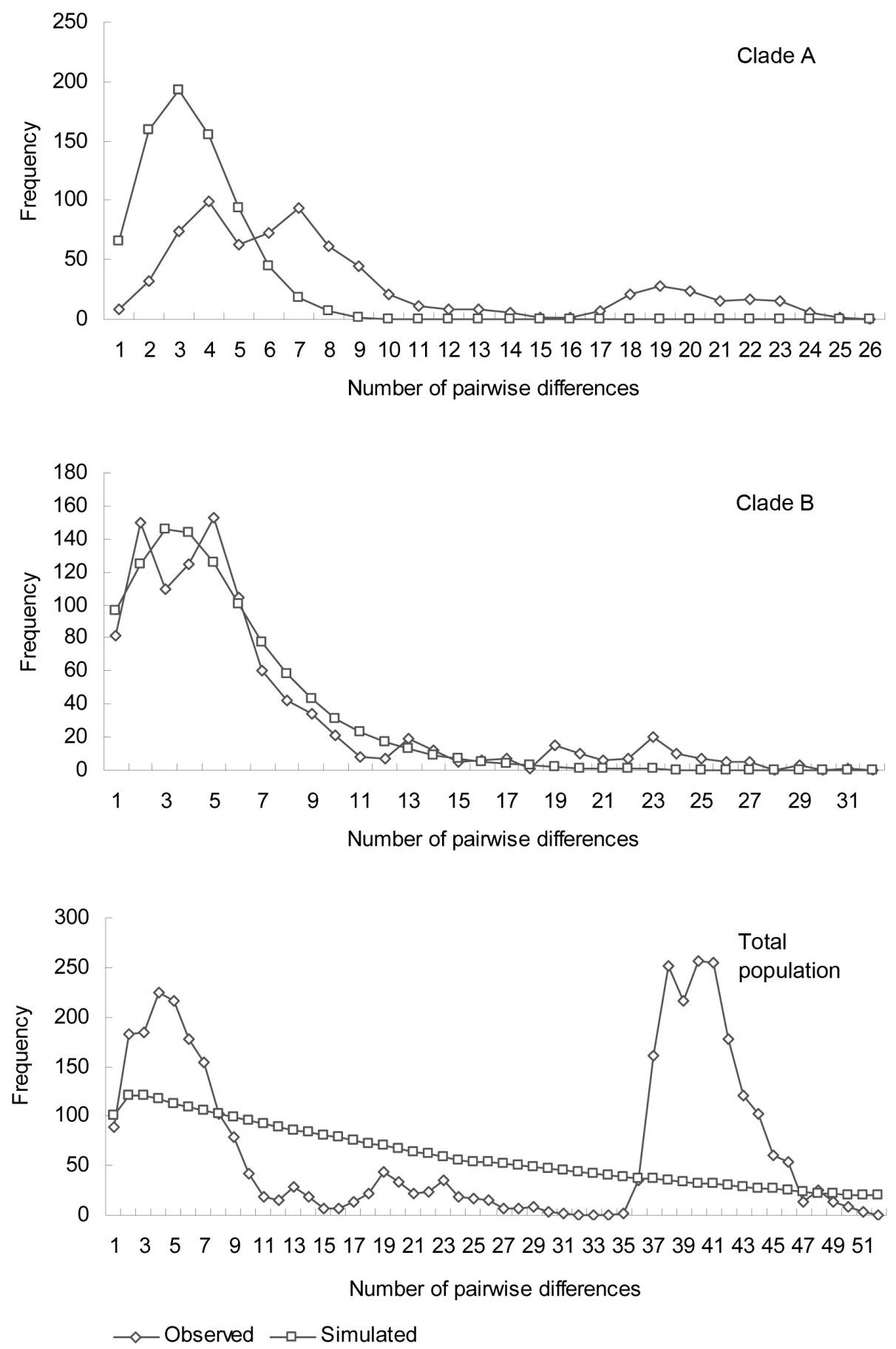

Figure 4. Mismatch distribution analysis of the total population and the clades. 


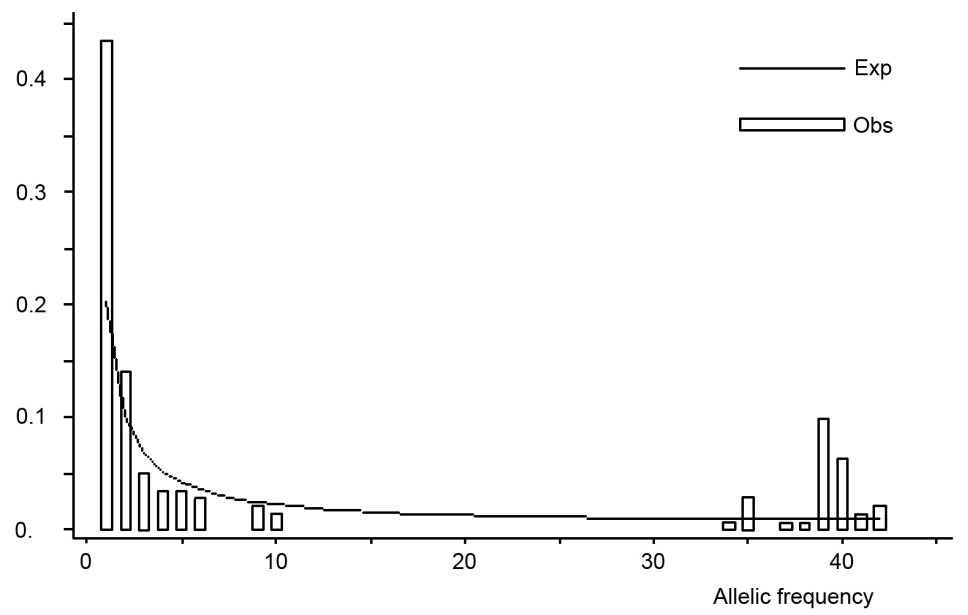

Figure 5. Allele frequency spectrum, indicating an excess of singleton mutations in cytochrome b and cytochrome c oxidase subunit I sequences.
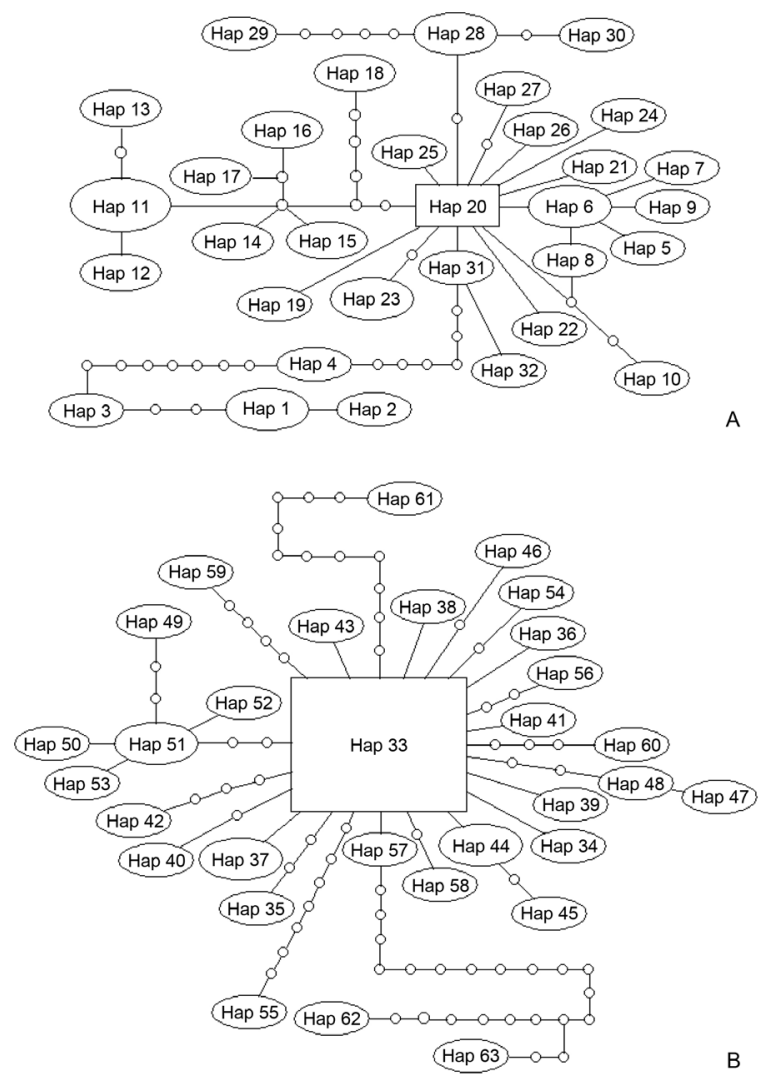

Figure 6. Minimum spanning tree of haplotypes. Each haplotype is represented by an ellipse or square (ancestor), with an area proportional to its frequency. 
vive in a range of different habitats (Xue et al., 2004; Torres-Díaz et al., 2007; Walker and Metcalf, 2008). All of these factors (except for hybridization) could have contributed to the high level of genetic diversity found in S. liupanensis. The species has probably undergone a history long enough to accumulate many mutations since its origin, and high gene flow can contribute to fixing mutations in a population. S. liupanensis once probably inhabited the entire Liupan Mountains; however, a recent population contraction occurred, probably due to anthropogenic activity and/or the degeneration of the environment. Multiple founder events are an alternative explanation for the high genetic diversity observed in this species, and it is possible that multiple founder events occurred during the history of this species. Multiple founder events have accumulated a high number of mutations in S. liupanensis. The two congeners of $S$. liupanensis are S. boulengeri and S. ningshanensis, and the nearest locations of these two species are $150 \mathrm{~km}$ and $250 \mathrm{~km}$, respectively, from the location of $S$. liupanensis, which makes it impossible for hybridization to have occurred between these three species. Therefore, hybridization did not contribute to the high genetic diversity found in S. liupanensis. S. liupanensis inhabits a range of different habitats, such as high mountains, streams, and different plant communities, and high habitat diversity contributes to high genetic diversity.

High gene flow, no significant genetic differentiation between most local populations, and the lack of a population structure suggest that habitat fragmentation did not occur in this species.

High levels of genetic variation in mtDNA cyt $b$ and COI suggest that there is a high genetic diversity in nuclear genes, although in general the evolutionary rate of mitochondrial DNA is higher than that of nuclear DNA. High genetic diversity is important in reducing the possibility of recessive homozygotes occurring, which are detrimental to the survival and development of the population. The probability of this occurring in species with a very narrow geographical range is much higher than in species with a wide geographical range, but high genetic diversity can certainly decrease the probability of recessive homozygotes occurring.

The Liupan Mountains are located in the arid interior of China, and have an unstable environment (Liu, 1984; Wang et al., 2003). Drought often threatens the Liupan Alpine toad. Frequent, severe drought may dramatically reduce the range of the toad, in which case few individuals would survive. Therefore, founder effects may occur frequently. The survival of local populations can be maintained with their existing genetic composition, since most of the variation was attributed to within and not between populations. Therefore, recovered populations would maintain the highest genetic diversity, and high genetic variation is beneficial to the survival and the development of the species.

The Alpine toad is limited to a very narrow geographical zone with a small population size, and lives in an environment threatened by frequent drought and anthropogenic activity. All of these factors have made it an endangered species. Effective conservation strategies and measures should be established as soon as possible; the most effective approach is to protect this species, to improve its environment, to expand its range, and to eventually increase its population size.

\section{ACKNOWLEDGMENTS}

We sincerely thank Mr. Penghai Qiao, Hao Yu, and Tianbin Ye for helping us to collect the samples and conduct the experiment. 


\section{REREENCES}

Aris-Brosou S and Excoffier L (1996). The impact of population expansion and mutation rate heterogeneity on DNA sequence polymorphism. Mol. Biol. Evol. 13: 494-504.

Avise JC (2000). Phylogeography: The History and Formation of Species. Harvard University Press, Cambridge.

Chenna R, Sugawarah Koike T, Lopes R, Gibson TJ, et al. (2003). Multiple sequence alignment with the Clustal series of programs. Nucleic Acids Res. 31: 497-500.

Clement M, Posada D and Crandall KA (2000). TCS: a computer program to estimate gene genealogies. Mol. Ecol. 9: $1657-1660$.

Crema S, Cristofolini G, Rossi M and Conte L (2009). High genetic diversity detected in the endemic Primula apennina Widmer (Primulaceae) using ISSR fingerprinting. Plant Syst. Evol. 280: 29-36.

Donnelly MJ, Licht MC and Lehmann T (2001). Evidence for recent population expansion in the evolutionary history of the malaria vectors Anopheles arabiensis and Anopheles gambiae. Mol. Biol. Evol. 18: 1353-1364.

Dupanloup I, Schneider S and Excoffier L (2002). A simulated annealing approach to define the genetic structure of populations. Mol. Ecol. 11: 2571-2581.

Excoffier L and Lischer HEL (2010). Arlequin suite ver. 3.5: a new series of programs to perform population genetics analyses under Linux and Windows. Mol. Ecol. Resour. 10: 564-567.

Excoffier L, Smouse PE and Quattro JM (1992). Analysis of molecular variance inferred from metric distances among DNA haplotypes: Application to human mitochondrial DNA restriction data. Genetics 131: 479-491.

Fu YX (1997). Statistical tests of neutrality of mutations against population growth, hitchhiking and background selection. Genetics 147: 915-925.

Gibson JP, Rice SA and Stucke CM (2008). Comparison of population genetic diversity between a rare, narrowly distributed species and a common, widespread species of Alnus (Betulaceae). Am. J. Bot. 95: 588-596.

Gitzendanner MA and Soltis PS (2000). Patterns of genetic variation in rare and widespread plant congeners. Am. J. Bot. 87: 783-792.

Hall TA (1999). BioEdit: a user-friendly biological sequence alignment editor and analysis program for Windows 95/98/ NT. Nucleic Acids Symp. Ser. 41: 95-98.

Hamrick JL and Godt MJ (1989). Allozyme Diversity in Plant Species. In: Plant Population Genetics, Breeding and Genetic Resources (Brown A, Clegg M, Khaler A and Weir B, eds.). Sinauer Press, Sunderland, 43-63.

Hamrick JL, Godt MJW and Sherman-Broyles SL (1992). Factors influencing levels of genetic diversity in woody plant species. New Forests 6: 95-124.

Hebert PDN, Penton EH, Burns JM, Janzen DH, et al. (2004). Ten species in one: DNA barcoding reveals cryptic species in the Neotropical skipper butterfly Astraptes fulgerator. Proc. Natl. Acad. Sci. U. S. A. 101: 14812-14817.

Huang YZ (1985). A new species of pelobatid toad (Amphibia: Pelobatidae) from Ningxia Hui Autonomous Region. Acta Biol. Plateau Sin. 4: 77-81.

Hudson RR, Slatkin M and Maddison WP (1992). Estimation of levels of gene flow from DNA sequence data. Genetics 132: 583-589.

Li R, Chen W, Tu L and Fu J (2009). Rivers as barriers for high elevation amphibians: a phylogeographic analysis of the Alpine stream frog of the Hengduan Mountains. J. Zool. 277: 309-316.

Librado P and Rozas J (2009). DnaSP v5: A software for comprehensive analysis of DNA polymorphism data. Bioinformatics 25: 1451-1452.

Liu DH (1984). A preliminary study on the climatic variation in the mountainous areas of South Ningxia. J. Ningxia Univ. 67-71.

Martel C, Viard F, Bourguet D and Garcia-Meuniera P (2004). Invasion by the marine gastropod Ocinebrellus inornatus in France. 1. Scenario for the source of introduction. J. Exp. Mar. Biol. Ecol. 305: 155-170.

Raduski AR, Rieseberg LH and Strasburg JL (2010). Effective population size, gene flow, and species status in a narrow endemic sunflower, Helianthus neglectus, compared to its widespread sister species, H. petiolaris. Int. J. Mol. Sci. 11: 492-506.

Ramos-Onsins SE and Rozas J (2002). Statistical properties of new neutrality tests against population growth. Mol. Biol. Evol. 19: 2092-2100.

Rogers AR (1995). Genetic evidence for a Pleistocene population explosion. Evolution 49: 608-615.

Rogers AR and Harpending H (1992). Population growth makes waves in the distribution of pairwise genetic differences. Mol. Biol. Evol. 9: 552-569.

Ronquist F and Huelsenbeck JP (2003). MrBayes3: Bayesian phylogenetic inference under mixed models. Bioinformatics 19: 1572-1574.

Schneider S and Excoffier L (1999). Estimation of past demographic parameters from the distribution of pairwise 
differences when the mutation rates vary among sites: application to human mitochondrial DNA. Genetics 152: 1079-1089.

Smouse PE, Long JC and Sokal RR (1986). Multiple regression and correlation extensions of the Mantel Test of matrix correspondence. Syst. Zool. 35: 627-632.

Swofford DL (2002). PAUP*: Phylogenetic Analyses Using Parsimony (*and Other Methods). Sinauer Associates, Sunderland.

Tajima F (1989). Statistical method for testing the neutral mutation hypothesis by DNA polymorphism. Genetics 123: 585-595.

Tajima F (1993). Measurement of DNA Polymorphism. In Mechanisms of Molecular Evolution. Introduction to Molecular Paleo Population Biology (Takahata N and Clark AG, eds.). Japan Scientific Societies Press, Sinauer Associates, Sunderland, 37-59.

Tajima F (1996). The amount of DNA polymorphism maintained in a finite population when the neutral mutation rate varies among sites. Genetics 143: 1457-1465.

Torres-Díaz CT, Ruizi E, González F, Fuentes G, et al. (2007). Genetic diversity in Nothofagus alessandrii (Fagaceae), an endangered endemic tree species of the coastal Maulino Forest of Central Chile. Ann. Bot. 100: 75-82.

Walker GF and Metcalf AE (2008). Genetic variation in the endangered Astragalus jaegerianus (Fabaceae, Papilionoideae): a geographically restricted species. Bull. Southern California Acad. Sci. 107: 158-177.

Wang LC, Ma L, Han YF and Jia ZK (2003). Discussion on the drought-resistant agro-technological system in south Ningxia. Agricult. Res. Arid Areas 21: 121-125.

Xue DW, Ge XJ, Hao G and Zhang CQ (2004). High genetic diversity in a rare, narrowly endemic primrose species: Primula interjacens by ISSR analysis. Acta Bot. Sin. 46: 1163-1169.

Zhang DF, Chen SL, Chen SY, Zhang DJ, et al. (2007). Patterns of genetic variation in Swertia przewalskii, an endangered endemic species of the Qinghai-Tibet Plateau. Biochem. Genet. 45: 33-50.

Zhang XL, Zhang DZ, Chu JM and Yang ZX (1998). A preliminary study on Scutiger liupanensis. J. Ningxia Agric. Coll. 19: 10-14. 